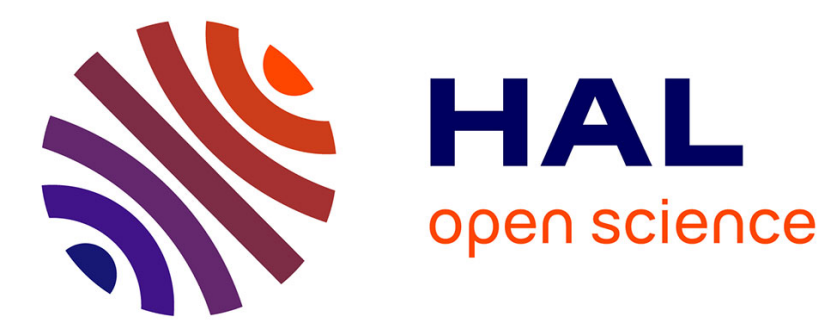

\title{
About the impact behavior of woven-ply carbon fiber-reinforced thermoplastic- and thermosetting-composites: A comparative study
} Benoît Vieille, Victor Manuel Casado, Christophe Bouvet

\section{- To cite this version:}

Benoît Vieille, Victor Manuel Casado, Christophe Bouvet. About the impact behavior of woven-ply carbon fiber-reinforced thermoplastic- and thermosetting-composites: A comparative study. Composite Structures, 2013, vol. 101, pp. 9-21. 10.1016/j.compstruct.2013.01.025 . hal-00859872

\section{HAL Id: hal-00859872 https://hal.science/hal-00859872}

Submitted on 9 Sep 2013

HAL is a multi-disciplinary open access archive for the deposit and dissemination of scientific research documents, whether they are published or not. The documents may come from teaching and research institutions in France or abroad, or from public or private research centers.
L'archive ouverte pluridisciplinaire HAL, est destinée au dépôt et à la diffusion de documents scientifiques de niveau recherche, publiés ou non, émanant des établissements d'enseignement et de recherche français ou étrangers, des laboratoires publics ou privés. 


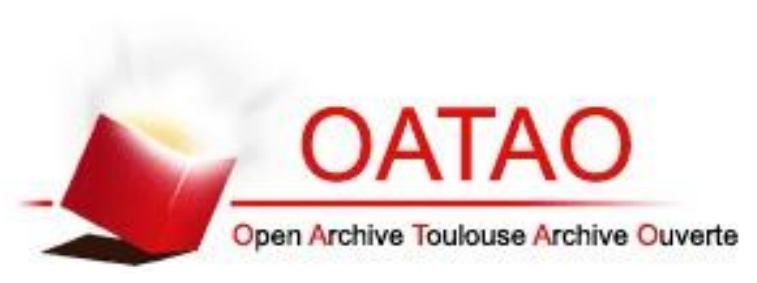

\section{Open Archive Toulouse Archive Ouverte (OATAO)}

OATAO is an open access repository that collects the work of Toulouse researchers and makes it freely available over the web where possible.

This is an author-deposited version published in: http://oatao.univ-toulouse.fr/ Eprints ID: 9328

To link to this article: DOI: $10.1016 /$ j.compstruct.2013.01.025

URL: http://dx.doi.org/10.1016/j.compstruct.2013.01.025

To cite this version: Vieille, Benoit and Casado, Victor Manuel and Bouvet, Christophe About the impact behavior of woven-ply carbon fiberreinforced thermoplastic- and thermosetting-composites: A comparative study. (2013) Composite Structures, vol. 101. pp. 9-21. ISSN 0263-8223 


\title{
About the impact behavior of woven-ply carbon fiber-reinforced thermoplastic- and thermosetting-composites: A comparative study
}

\author{
B. Vieille ${ }^{\mathrm{a}, *}$, V.M. Casado ${ }^{\mathrm{b}}$, C. $_{\text {Bouvet }}{ }^{\mathrm{b}}$ \\ a INSA Rouen - Groupe de Physique des Matériaux, UMR 6634 CNRS, 76801 St. Etienne du Rouvray, France \\ ${ }^{\mathrm{b}}$ Univ. de Toulouse, INSA, UPS, Mines Albi, ISAE - ICA, 10 av. E. Belin, 31055 Toulouse cedex 4, France
}

\section{A R T I C L E I N F O}

Keywords:

Polymer-matrix composites

Woven fabrics

Impact behavior

Mechanical testing

\begin{abstract}
A B S T R A C T
This study is aimed at comparing the response of TS-based (epoxy) and TP-based (PPS or PEEK) laminates subjected to low velocity impacts. C-scan inspections showed that impact led to diamond-shaped damage resulting from different failure mechanisms: fiber breakages in warp and weft directions, more or less inter-laminar and intra-ply damage, and extensive delamination in C/PEEK and C/epoxy laminates. The permanent indentation can be ascribed to specific mechanisms which mainly depend on many factors including the ultimate out-of-plane shear strength, and the interlaminar fracture toughness in modes I-II-III. In TP-based laminates, the matrix plasticization seems to play an important role in matrix-rich areas by locally promoting permanent deformations. Fiber-bridging also prevents the plies from opening in mode I, and slows down the propagation of interlaminar and intralaminar cracks in modes II-III. Both mechanisms seem to reduce the extension of damages, in particular, the subsequent delamination for a given impact energy. In epoxy-based laminates, the debris of broken fibers and matrix get stuck in the cracks and the adjacent layers, and create a sort of blocking system that prevents the cracks and delamination from closing after impact.
\end{abstract}

\section{Introduction}

Polymer matrix composite laminates are prone to delamination when impacted, resulting in low damage tolerances, which is of great concern for load carrying applications. To discuss the impact behavior of polymer matrix composites it is initially helpful to consider the nature of constitutive materials and the reinforcement type [1]. The use of thermoplastics (denoted TP) predominates in unreinforced materials as well as in short fiber-reinforced composites. Long and continuous fiber-reinforced composites are still dominated by thermosetting (TS) polymer matrices, because they are particularly suited for impregnation into the fibers reinforcement. Thus, TS matrix composites have been extensively used over the past 40 years in aeronautical applications. Even though they display interesting mechanical properties, they also present undeniable drawbacks, such as the need for low-temperature storage, a hard-to-control cure process, a very long curing process, and handmade draping, which causes most of the irreversible defects of the manufacturing process. In such an environment, high-performance thermoplastic resins (e.g. PEEK and PPS) offer a promising alternative to TS resins. Indeed, semi-crystalline TPs resins offer a number of advantages over conventional TS resins (such as epoxies): a high

\footnotetext{
* Corresponding author. Tel.: +33 232959756.

E-mail address: benoit.vieille@insa-rouen.fr (B. Vieille).
}

degree of chemical resistance, excellent damage and impact resistances, and they may be used over a wide range of temperatures. Lastly, there are numerous engineering reasons why TP composites are attractive as aerostructures: increased toughness compared with TS resins, inherent flame retardancy, and they are associated with low-cost manufacturing processes like thermofolding, stamping, welding and co-consolidation.

\section{Literature review}

As low velocity impact is one of the most detrimental solicitations for laminates, high-performance TPs are considered in composites structures mainly for damage tolerance. Impact-induced damage is particularly critical because it drastically reduces the residual mechanical properties of the structure [2-4]. Very few authors have compared the impact behavior of TS- and TP-based composite structures, and their effects on residual strength [5-10], as well as the damage tolerance of UD-ply and woven-ply laminates [10-12]. It appears from literature that TP-based composites display a better resistance to the impact damage than epoxy-based composites. The brief literature review, herein, is not aimed at giving a general overview of the impact behavior of TS-based laminates for which a great number of references are available in the literature $[2,13-15]$. In the early 90 s, the impact performance and damage tolerance of TP-based composites had 
been studied in order to understand why such materials were often more damage tolerant than TS-based composite materials $[16,17]$. To this aim, a few authors have investigated the influence of matrix type and morphology on the ability of TP-based composites to withstand penetration [18,19], absorb energy, and sustain damage at different temperature levels. Most of the studies about the impact performance, and damage tolerance of TP-based composites deal with PEEK-based composites [8,9,20-23]. However, only very few references report the impact behavior of PPS-based laminates [7,20,24-27]. The impact energy adversely affects the impact performance of the laminates, whereas the effect of impact velocity is found to be insignificant. Among the properties governing the impact behavior of laminated composites, the critical strain energy release rates $G_{I C}$ and $G_{I I C}$ are of the utmost importance, and are associated with the mode I and mode II interlaminar fracture toughness [28-31]. In addition to the contribution of the matrix toughness to the impact performance of a composite system, the impact behavior and the damage tolerance are also importantly influenced by the reinforcement architecture. The issue of the specific impact behaviors of UD-ply laminates and woven-ply laminates has been well addressed in [10-12,19,20,32-37,38]. An illustration of the important contribution of fiber reinforcement to impact behavior is emphasized by Ghaseminejad et al. who

Table 1

Material properties of the different composite systems [41].

\begin{tabular}{|c|c|c|c|c|}
\hline & & C/PEEK & C/PPS & C/epoxy (914) \\
\hline Average thickness (mm) & & 2.25 & 2.29 & 2.4 \\
\hline $\operatorname{Price}^{\mathrm{a}}(€ / \mathrm{kg})$ & & 145 & 100 & 200 \\
\hline Density $\left(\mathrm{g} \mathrm{cm}^{-3}\right)$ & & 1.54 & 1.56 & 1.48 \\
\hline Yield strength $\tau_{x y}$ at $0.2 \%(\mathrm{MPa})$ & & 64 & 53 & 56 \\
\hline \multirow[t]{2}{*}{ Ultimate strength (MPa) } & $\tau_{x y}^{u}$ & 149 & 115 & 116 \\
\hline & $\tau_{x y}^{u}$ & 83 & 54 & 68 \\
\hline$E_{x x}(\mathrm{GPa})$ & & 59.1 & 56.5 & 63.3 \\
\hline$E_{y y}(\mathrm{GPa})$ & & 59.4 & 58.2 & 63.7 \\
\hline
\end{tabular}

a The price is given by the company Aircelle and includes all the steps required to get a consolidated plate from the raw materials. studied the impact behavior and damage tolerance of two thermoplastic (PEEK and PPS) reinforced with carbon fiber woven fabric [20]. This reference presents a good overview of the failure mechanisms of woven-fabric laminates in mode I and mode II delamination, and under impact loading. Potential advantages of using woven fabrics as opposed to cross-ply UD prepreg tapes are observed: woven-fabric laminates exhibit much higher $\mathrm{G}_{I C}$ values (often more than 4-5 times) than the UD counter-parts. The unique features and advantageous failure mechanisms are identified: inherent roughness of the fabric [39]; the availability of matrixrich regions between the fabrics; crack propagation along the undulating pattern of the yarns creating a large fracture surface area; and multiple crack fronts delamination [12]. Thus, wovenply laminates usually display reduced maximum loads, smaller damage areas, higher ductility and residual CAI strength than UD-ply laminates [34], mainly because of higher mode II interlaminar fracture toughness. At last, even though the qualification of the impact damage (size and severity of damage, permanent indentation) remains difficult, standard nondestructive evaluation methods such as ultrasonic C-scan imaging are often used, particularly when it comes to detect delamination in polymer-based composites [40]. From this literature review, it seems necessary to look further into matrix's specific contribution to the impact performance, and damage tolerance of different types of wovenply laminates. To this aim, low velocity impact tests have been conducted at different impact energies. Fractography and C-scan inspections have also been performed to identify the damage mechanisms and the delaminated area. In order to assess the severity of damage, CAI tests results will be presented in a forthcoming paper.

\section{Experimental setup}

\subsection{Materials}

The composite materials studied in this work are carbon fabricreinforced prepreg laminated plates consisting of different matrix

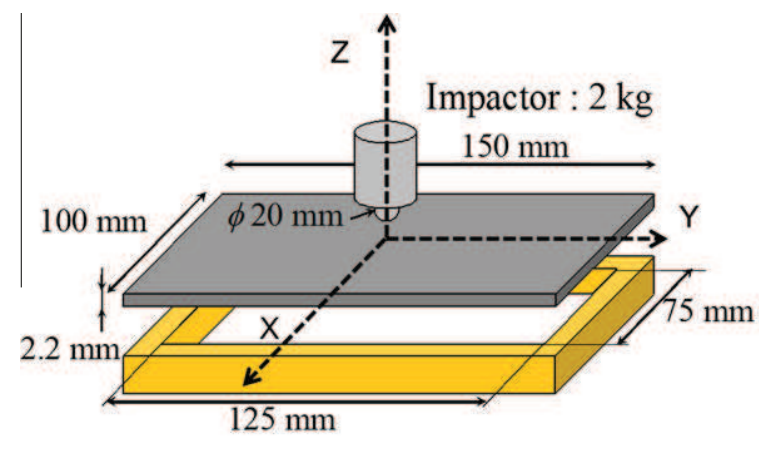

Standard AITM 1-0010

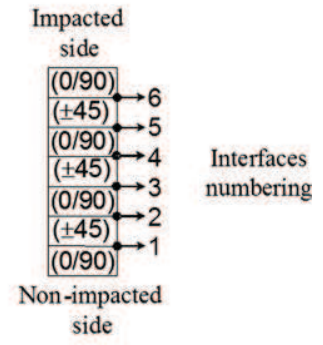

(b)

Fig. 1. Reference case: (a) impact set up, and (b) stacking sequence of the laminate.

Table 2

Results of impact tests for different impact energies.

\begin{tabular}{|c|c|c|c|c|c|c|c|c|c|c|c|c|c|c|c|}
\hline \multirow[b]{2}{*}{$E_{\text {impact }}(\mathrm{J})$} & \multicolumn{5}{|c|}{ C/PEEK } & \multicolumn{5}{|c|}{ C/PPS } & \multicolumn{5}{|c|}{ C/epoxy } \\
\hline & 1.88 & 5.92 & 10.25 & 16.95 & 23.65 & 1.73 & 5.78 & 10.37 & 16.9 & 24.4 & 1.75 & 5.85 & 10.3 & 17.4 & 25 \\
\hline Delaminated surface $\left(\mathrm{mm}^{2}\right)$ & 0 & 52 & 191 & 555 & 900 & 0 & 42 & 230 & 445 & 600 & 0 & 142 & 434 & 763 & 978 \\
\hline Max. displacement (mm) & 2.61 & 4.66 & 6.19 & 8.59 & 11.36 & 2.5 & 4.44 & 6.31 & 8.34 & 11.35 & 2.42 & 4.55 & 6.47 & 9.9 & Perforation \\
\hline$E_{\text {dissipated }}(\mathrm{J})$ & 0.45 & 3.44 & 6.74 & 13.48 & 20.87 & 0.3 & 2.96 & 6.79 & 13.05 & 21.94 & 0.64 & 3.7 & 7.78 & 16 & 22.6 \\
\hline$E_{\text {dissipated }} / E_{\text {impact }}(\%)$ & 24 & 58 & 66 & 80 & 88 & 17 & 51 & 65 & 77 & 90 & 37 & 63 & 76 & 92 & 90 \\
\hline
\end{tabular}


systems: TP (PPS or PEEK) and TS (epoxy). The PPS resin (Fortron 0214) is supplied by Ticona, the PEEK resin (grade 150) is supplied by Victrex, and the epoxy resin (914) is supplied by Hexcel. The woven-ply prepreg laminate consists of 5-harness satin weave car- bon fiber fabrics whose reference is T300 $3 \mathrm{~K}$ 5HS, and is supplied by SOFICAR. The volume fraction of fibers is $50 \%$. The prepreg plates are hot pressed according to a Quasi-Isotropic lay-up: $[(0,90) /( \pm 45) /(0,90) /( \pm 45) /(0,90) /( \pm 45) /(0,90)]$ in TP-based lami-

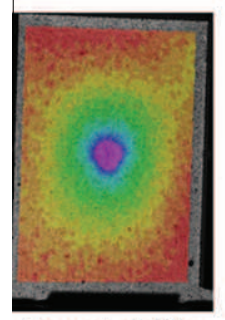

Impacted side

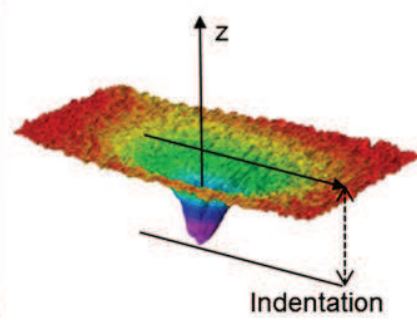

(a)

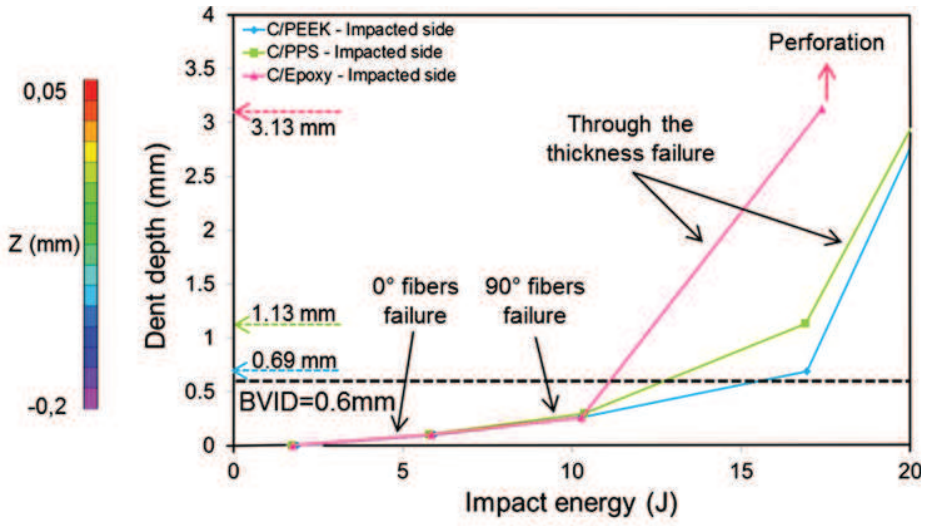

(b)

Fig. 2. Dent depth: (a) contour plot and corresponding 3-D image of damaged specimen, and (b) changes in dent depth as a function of the impact energy on the impacted side of specimens.
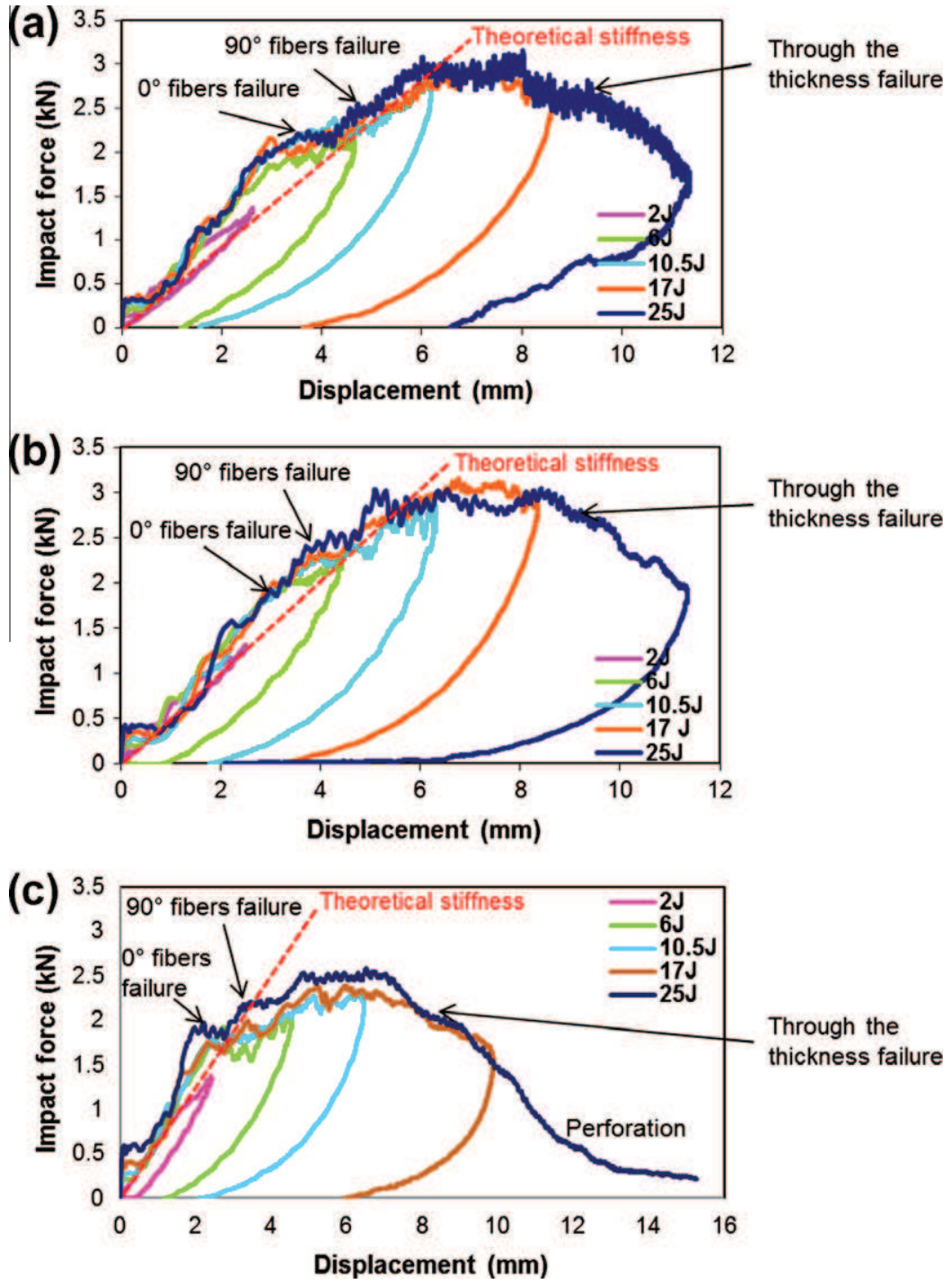

Fig. 3. Load-displacement responses to increasing impact energies: (a) C/PEEK, (b) C/PPS, and (c) C/epoxy. 
nates, and $[(0,90) /( \pm 45) /( \pm 45) /(0,90) /(0,90) /( \pm 45) /( \pm 45) /(0,90)]$ in C/epoxy. The lay-up slightly differs in order to get similar laminates' thicknesses. The laminates' thickness was averaged from measurements at different points: $2.25 \mathrm{~mm}$ in C/PEEK, $2.29 \mathrm{~mm}$ in C/PPS, and $2.4 \mathrm{~mm}$ in C/epoxy laminates. The specimens were cut into $600 \times 600 \mathrm{~mm}^{2}$ flat panels with a water-cooled diamond saw. Specimens are $100 \times 150 \mathrm{~mm}^{2}$ plates, and complies with the standard Airbus AITM 1-0010, except for the recommended thickness $(4 \mathrm{~mm})$. The main mechanical properties (see Table 1 ) of the three composite systems investigated in this work have been evaluated in previous works $[28,41,42]$.

\subsection{Experimental procedure}

Low velocity impact tests have been conducted at room temperature on the three composite materials for different impact energies ranging from $2 \mathrm{~J}$ ( $\left.v_{\text {indentor }} \approx 1.4 \mathrm{~m} / \mathrm{s}\right)$ to $25 \mathrm{~J}\left(v_{\text {indentor }} \approx 5 \mathrm{~m} / \mathrm{s}\right)$ such as: $2 \mathrm{~J}, 6 \mathrm{~J}, 10.5 \mathrm{~J}, 17 \mathrm{~J}, 25 \mathrm{~J}$. The tests were conducted using a guided drop weight tester characterized by a hemispherical steel indentor (diameter $=20 \mathrm{~mm}$ ), and an impactor whose weight is $2.077 \mathrm{~kg}$ (see Fig. 1). The drop tower also consists of an optical sensor used to evaluate the initial velocity before the impact, a piezoelectric force sensor to measure the impact load. Two specimens have been tested in each configuration. According to the previous standard, the BVID (Barely Visible Impact Damage) is defined by $0.6 \mathrm{~mm}$ of indentation after relaxation of the structure and without being exposed to any humidity [43]. The data acquisition is achieved using a Yokogawa DL708 digital oscilloscope, which monitors two types of signals (force and intensity of the laser beam) at $200 \mathrm{kHz}$ frequency. Finally, the impact damage was assessed by subsequent C-scan inspection and microscopic assessment of impacted specimens.

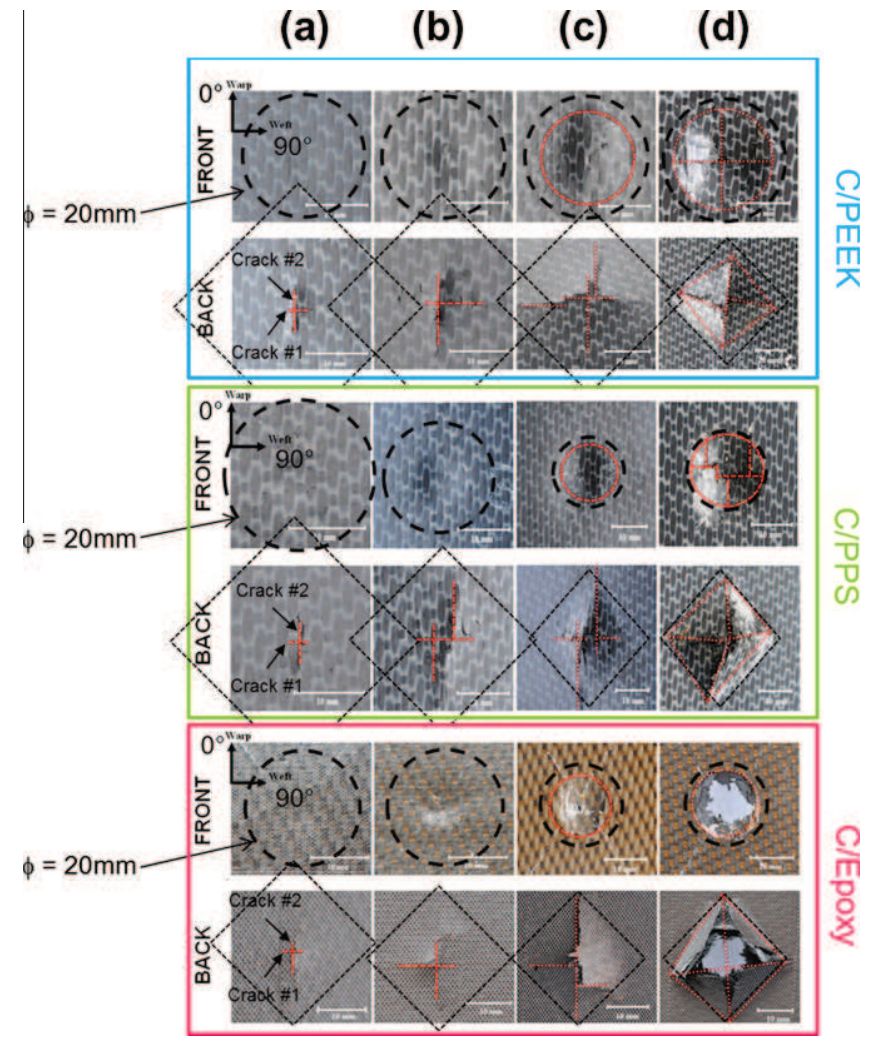

Fig. 5. Observations of impact damage patterns on front and back sides of impacted specimens as a function of the impact energy: (a) $6 \mathrm{~J}$, (b) $10.5 \mathrm{~J}$, (c) $17 \mathrm{~J}$, and (d) $25 \mathrm{~J}$.
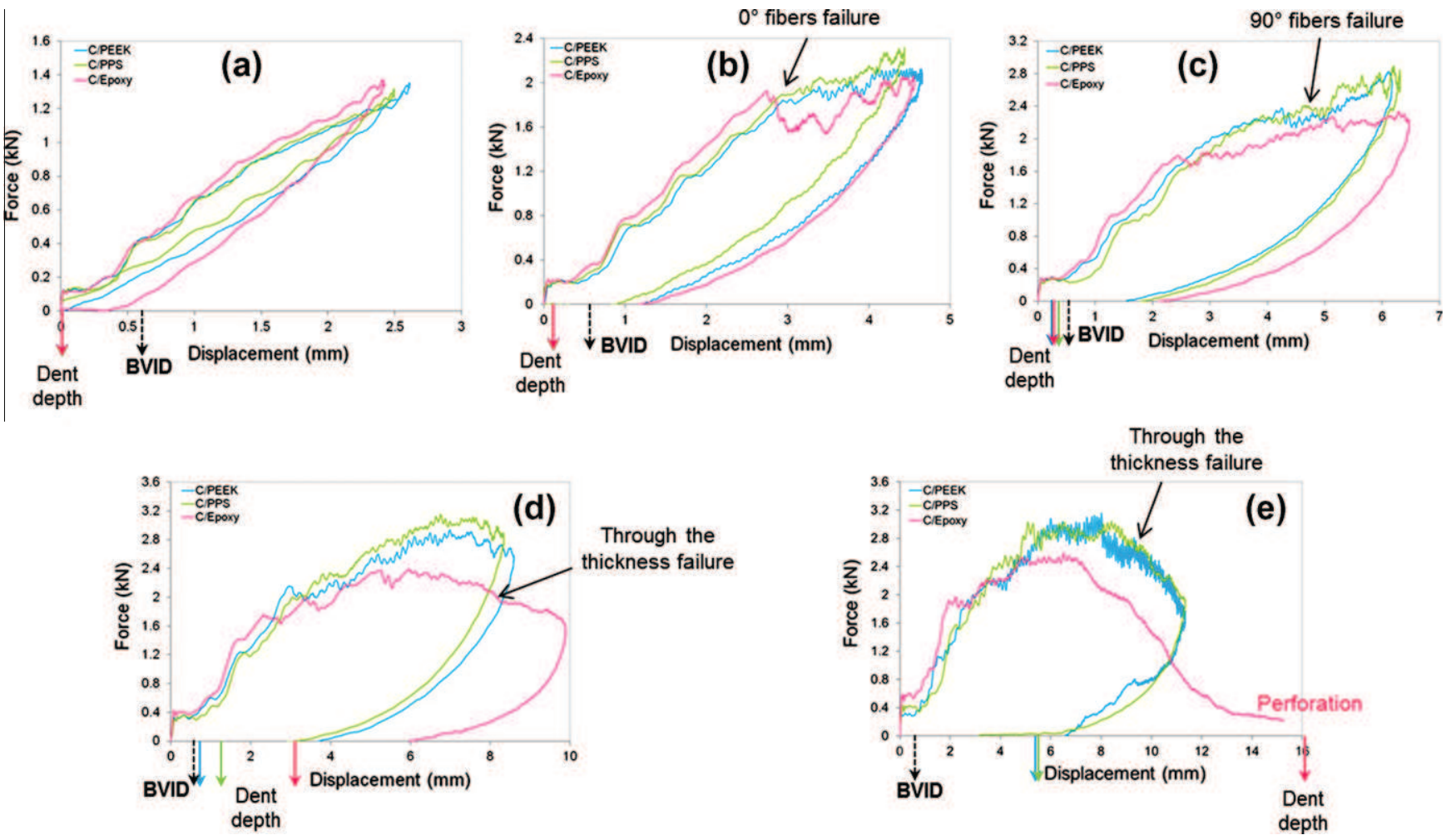

Fig. 4. Comparison of load-displacement curves for the three materials and every impact energy: (a) $2 \mathrm{~J}$, (b) $6 \mathrm{~J}$, (c) $10.5 \mathrm{~J}$, (d) $17 \mathrm{~J}$, and (e) $25 \mathrm{~J}$. 


\section{Results}

\subsection{Permanent indentation}

Laminates can absorb the impact energy by different means including indentation (representative of local matrix crushing and local fiber breakage), delamination (inter-yarn fracture), splitting (intra-yarn fracture) or fibers peeling on the non-impacted side $[25,44,45]$. For every impact energy, it appears that C/epoxy presents the highest ratio of dissipated energy compared with impact energy, whereas the energy dissipated during impact is virtually the same in C/PPS and C/PEEK (see Table 2). Such a ratio usually increases to reach a maximum value at the onset of perforation, as can be observed in the C/epoxy case [26]. The measurement of the specimen's indentation is typically used to assess the impact damage. In general, the indentation just after the impact (temporary indentation), is always higher than the indentation after relaxation of the impacted composite. Such relaxation effects can be neglected after $48 \mathrm{~h}$ to get the permanent indentation $[45,46]$. The indentation (see Fig. 2a), also called dent depth, is measured using a dial indicator with an error of $\pm 0.01 \mathrm{~mm}$ at several locations and according to different directions of the specimen. In TP-based laminates, the BVID $(0.6 \mathrm{~mm})$ is reached at about $13 \mathrm{~J}$ (C/PPS) and $16 \mathrm{~J}(\mathrm{C} / \mathrm{PEEK})$, whereas it is reached at about $11 \mathrm{~J}$ in $\mathrm{C} /$ epoxy (see Fig. 2b).

\subsection{Force-displacement curves}

The force-displacement curves show the specimen's stiffness (slope of the curve), the maximum displacement, and some information about damage for every impact energy (see Figs. 3 and 4). For the maximum impact energy $(25 \mathrm{~J})$, the force-displacement curve can globally be divided into four main parts [45]. The first part of the curve is linear and represents the stiffness of the nondamaged specimen. For comparison purposes, the red-dotted line represents the theoretical stiffness calculated from the plates' theory. At a force level of $2 \mathrm{kN}$ and a deflection of $3 \mathrm{~mm}$ (for laminates' average thicknesses of about $2.3 \mathrm{~mm}$ ), the load-deflection curves of C/PEEK and C/PPS show a clear change in stiffness (see Fig. 3a and $\mathrm{b}$ ), indicating damage initiation. In epoxy-based specimens,
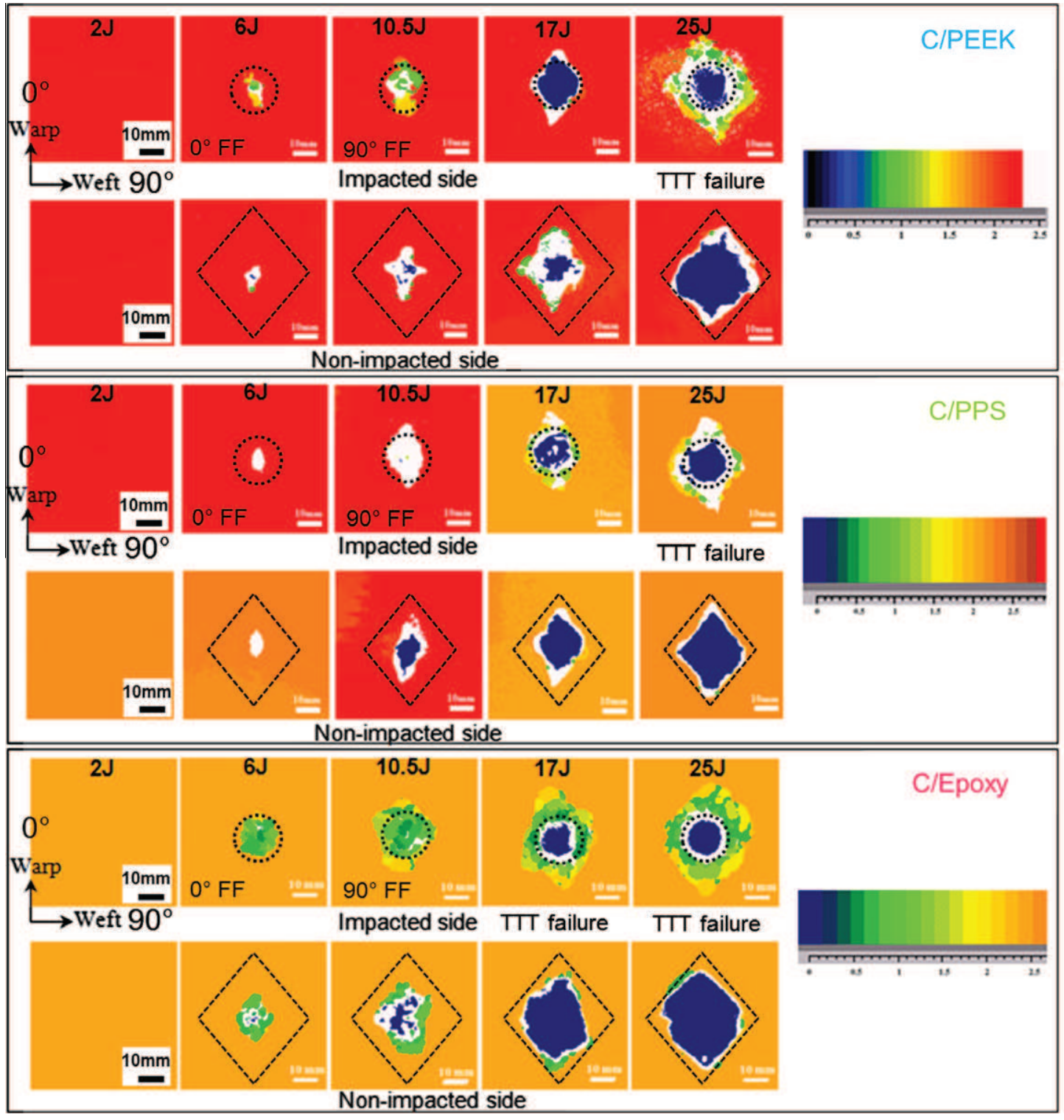

FF: fibers failure

TIT failure: Through the thickness failure

Fig. 6. C-scan inspection of impacted specimens. 
stiffness changes for an impact force of about $2 \mathrm{kN}$ (see Fig. 3c), and a deflection of the plate of about $2.8 \mathrm{~mm}$ (for laminates' average thicknesses of about $2.4 \mathrm{~mm}$ ). The previous observations suggest that damage appears as a result of the same impact forces in the studied composite systems, indicating the start of the second part. Once the material's stiffness has changed during low velocity impact tests, the profile of the force-displacement curve is unique to each material. However, a few common features can be observed in the three composite systems: the sawtooth profile is associated with the specific impact damage that will be discussed further. At some point during the impact test and depending on the impact energy, the maximum force borne by the laminates can be determined in the third part of the typical impact force-displacement curve. A threshold seems to appear at about $3 \mathrm{kN}$ for $10.5 \mathrm{~J}$, $17 \mathrm{~J}$ and $25 \mathrm{~J}$ impact energies. On the one hand, the maximum force reached in C/PPS is always equal or slightly higher than the one reached in C/PEEK. A maximum force threshold (about $3 \mathrm{kN}$ ) seems to be reached at $17 \mathrm{~J}$. On the other hand, C/epoxy laminates perform similarly to TP composites from $2 \mathrm{~J}$ to $6 \mathrm{~J}$ impact energies. After this threshold, the force gradually decreases to reach the last part of the curve when the force becomes equal to zero. For higher impact energies, there are two main differences: the force threshold is lower $(2.4 \mathrm{kN})$, and the $25 \mathrm{~J}$ impact causes the specimen's perforation, hence justifying a residual force at the end of the test. For a relevant comparison of the impact performance of the three materials, force-displacement curves have been compared for every impact energy (see Fig. 4). C/epoxy laminates present the lowest impact resistance for all impact energies, whereas TP-based laminates display a rather similar impact damage behaviors in terms of force-displacement responses. The inflection and the sudden drops (associated with a type of damage that will be discussed in the next section) observed on the force-displacement curves are virtually the same for impact forces less than $2 \mathrm{kN}$. For higher force levels, the profile of these curves depends on specific impact damage scenarios which can be analyzed from the macroscopic observations (see Fig. 5), the C-scan inspections (see Fig. 6), and the microscopic observations of $0^{\circ}$ and $90^{\circ}$ cuts of impacted specimens (see Figs. 9-11). On the load-displacement curves, the dent depth of each material can be compared for every impact energy (see Fig. 4).

\subsection{Macroscopic observations of impacted specimens}

Macroscopic views of the front (impacted side) and the back (non-impacted side) of specimens give first information about the onset of damage as a function of the impact energy (see Fig. 5). The hemispherical indentor (impacted side), and the diamondshaped fracture surface (non-impacted side), each corresponding to the maximum $25 \mathrm{~J}$ impact energy, are both represented on each macroscopic view. The scale has been adapted for each view in order to make the observed damages clearer. The $2 \mathrm{~J}$ impact does not cause important damage to specimens, whereas the $25 \mathrm{~J}$ impact induces the maximum damage in comparison to other energy levels. For the three materials, the onset of cracks along warp/weft directions is observed on the non-impacted side of specimens from $6 \mathrm{~J}$ impact energy. On Fig. 5a these cracks are represented by red-dotted lines, and are referenced as transverse crack \#1 (along the weft direction) and longitudinal crack \#2 (along the warp direction). At $10.5 \mathrm{~J}$, the length of cracks appearing at $6 \mathrm{~J}$ along warp/weft directions has increased in all cases, but a new crack along the warp direction can be observed in PPS-based specimens (see Fig. 5b). At $17 \mathrm{~J}$, the hemispherical indentation on the impacted side becomes clear (this is the first energy that creates an indentation over the BVID in TP specimens). In addition, fibers' splitting starts generalizing, and cracks along warp/weft directions significantly developed on the non-impacted side (see Fig. 5c). A $17 \mathrm{~J}$ impact importantly penetrates $\mathrm{C} /$ epoxy laminates, and the main $90^{\circ}$ crack is longer on the non-impacted side, whereas a new crack has appeared along the warp direction. On the non-impacted side of PEEK-based specimens, there are also new cracks along warp/weft directions, and a cross-shape fracture surface can be observed. Lastly, the $25 \mathrm{~J}$ impact importantly penetrates C/PEEK and C/PPS laminates, and perforates C/epoxy laminates (see Fig. 5d). The non-impacted side of all specimens can be characterized by diamond-shaped fracture surfaces.

\subsection{Post impact C-scan inspections}

The C-scan maps of impacted specimens provide further information on the damage mechanisms (see Fig. 6), and more particularly they are often used to calculate the delaminated area (see Table 3) which is related to the dissipation of energy during the im-

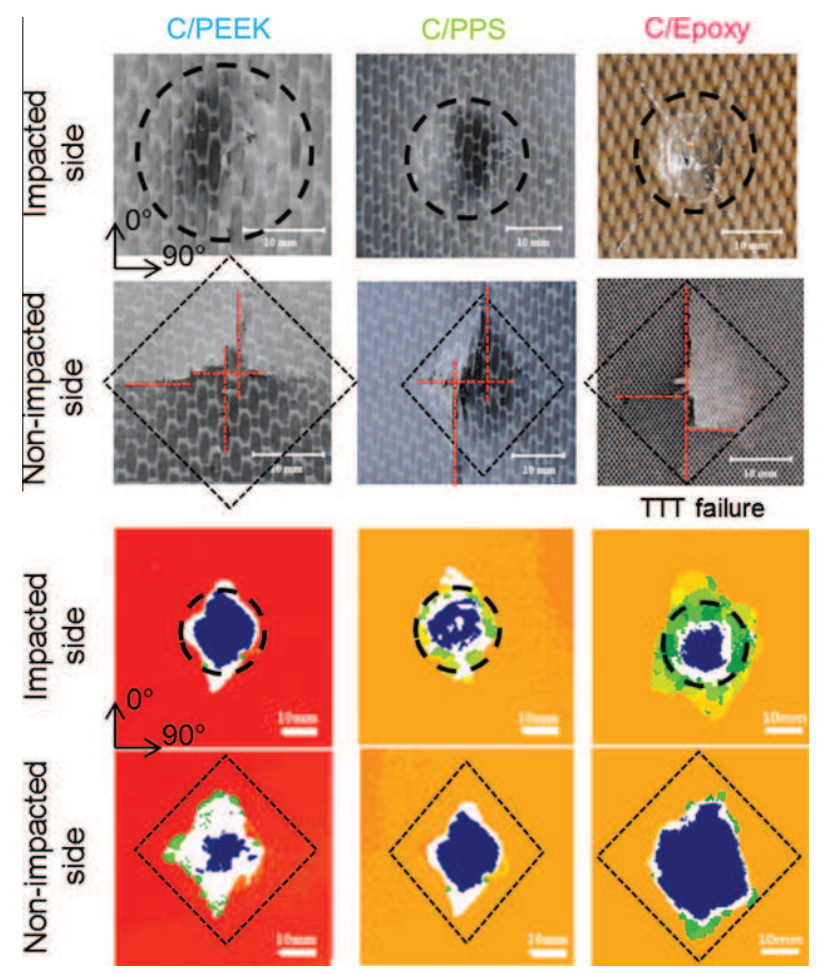

Fig. 7. Comparison of C-scan maps and impact damage patterns on front and back sides of specimens impacted at $17 \mathrm{~J}$ : (a) C/PEEK, (b) C/PPS, and (c) C/epoxy.

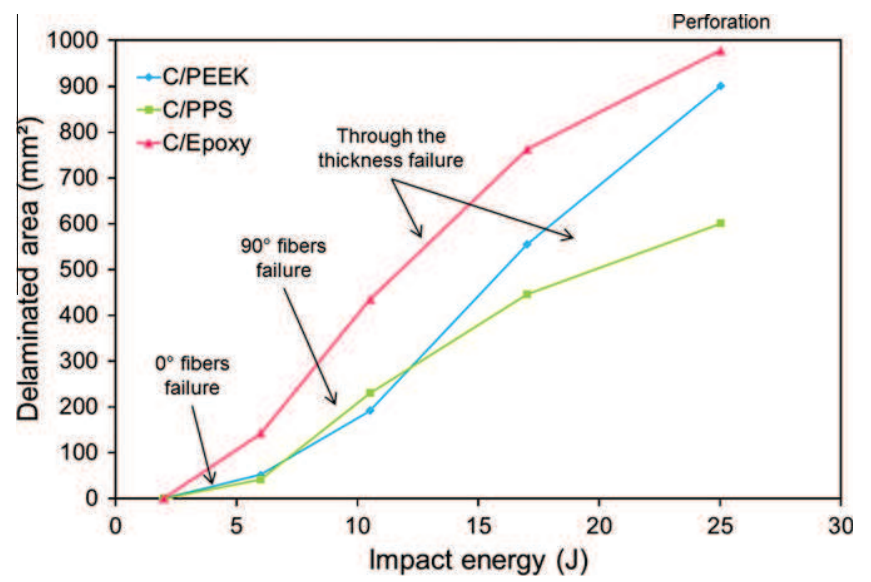

Fig. 8. Changes in the delaminated areas resulting from $\mathrm{C}$-scan results as a function of impact energy. 
pact (see Table 2). On each C-scan map is represented by either the hemispherical indentor (impacted side) or the diamond-shaped fracture surface (non-impacted side) corresponding to the $25 \mathrm{~J} \mathrm{im-}$ pact energy. For each material, the damage area is similar on both impacted/non-impacted sides of laminates. C/epoxy specimens always display larger delaminated areas than TP-based composites, reaching values about twice as high for low impact energies. For higher impact energies, the relative difference in delaminated areas remains significant (about $70 \%$ ) when comparing C/epoxy and C/PPS impacted specimens (see Fig. 8). The comparison of epoxy- and PEEK-based laminates shows that the relative difference in delaminated areas decreases as impact energy increases going from $+40 \%$ ( $17 \mathrm{~J}$ ) to only $+10 \%$ ( $25 \mathrm{~J}$ ). Finally, the delaminated area is considerably more expanded in C/PEEK than in C/PPS laminates $(+25 \%$ at $17 \mathrm{~J}-+50 \%$ at $25 \mathrm{~J})$. As a conclusion to this section, it appears that C/epoxy is prone to delamination during low-velocity impacts. It turns out that PEEK-based specimens tend to delaminate to an increasing extent at increasing impact energy, whereas PPS-based laminates display limited delamination.

\section{Analysis and discussion}

5.1. About the influence of the mesostructure on the impact damage mechanisms

The primary impact failure mechanisms are a very complex combination of energy absorption mechanisms such as delamina- tion predominantly caused by modes I-II interlaminar shear matrix cracking, and intralaminar fracture in terms of fiber fracture and kinking or splitting [11]. In woven-ply laminates, the fiber bundles crimps cause local stress perturbations under uniaxial tension, which lead to the concentration of large normal and shear strains. These strains concentrations may result in early damage initiation in the form of fiber/matrix interface debonding or matrix cracking. Even though the weave structure prevents the fiber bundles from migrating into the interply layer during fabrication, the deviation of fabric surface from planarity introduces macroscopic roughness, depending on the fabric thickness as well as the weaving patterns. The roughness of fabrics perpendicular to the direction of crack growth also promotes the creation of a larger fracture-surface area, and matrix-rich regions at the crimps between warp/weft yarns and between laminates' plies. These matrix-rich regions seem to play an important role in the impact behavior as it will be discussed further. During low velocity impacts, the first type of damage is matrix cracking, which does not significantly change the overall stiffness of laminates $[2,27]$. Such damage depends on the ultimate out-of-plane $\left(\tau_{x z}^{u}\right)$ and in-plane $\left(\tau_{x z}^{u}\right)$ shear strengths respectively [28]. In order to investigate the impact mechanisms associated with the tested material, it is therefore necessary to compare their ultimate shear strengths (see Table 1): $\tau_{x z}^{u}$ is $54 \%$ and $22 \%$ higher in C/PEEK laminates with respect to C/PPS and C/epoxy respectively, whereas $\tau_{x z}^{u}$ is about 30\% higher. At some point during the impact damage process, lots of intralaminar and inter-yarn cracks appear, and ultimately coalesce to create a pyramidal damage (see Figs. 9-

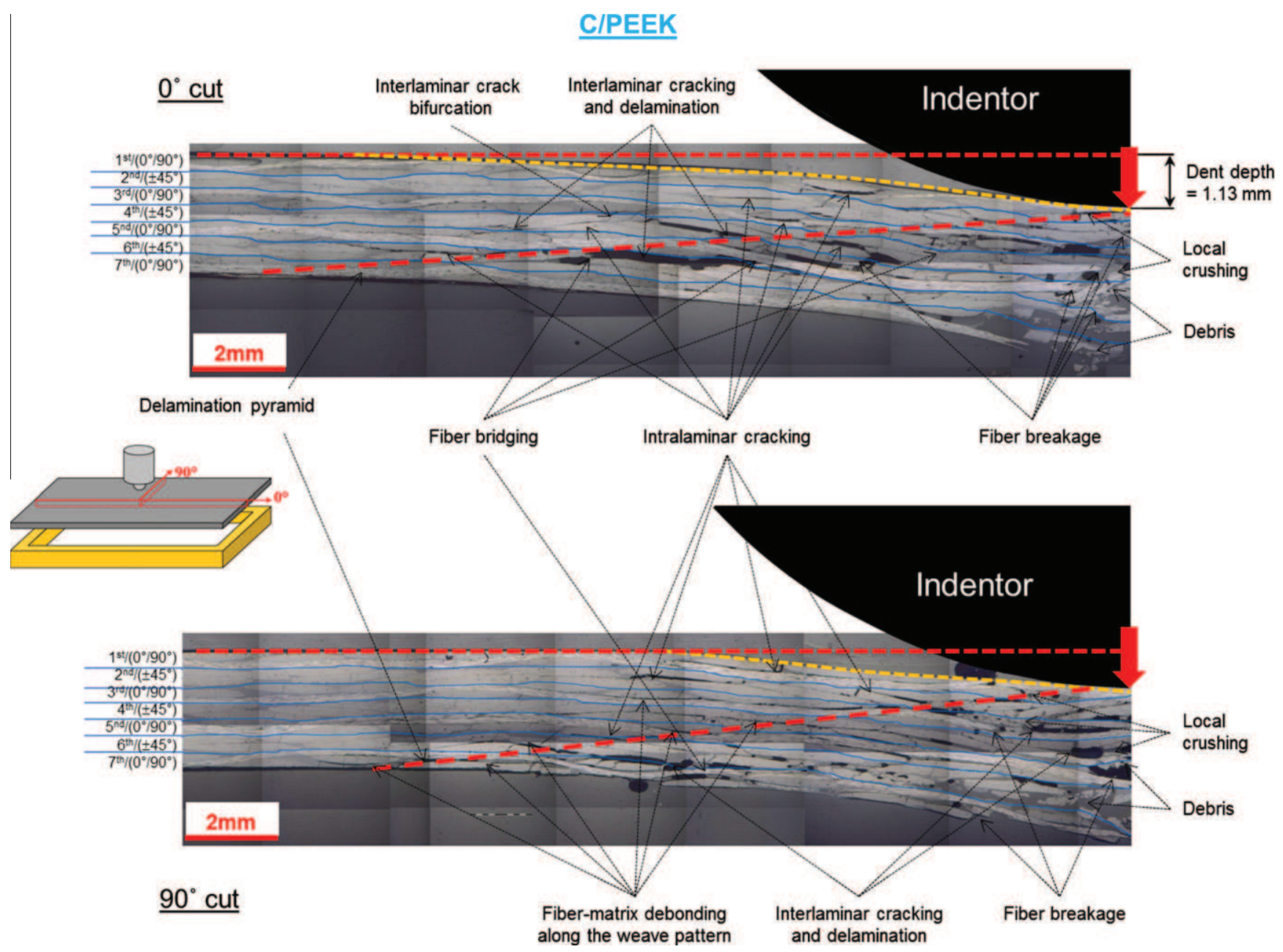

Fig. 9. Microscopic observations of C/PEEK specimens impacted at $17 \mathrm{~J}$. 
11). These cracks are important because cracks tips are known to act as onset sites for delamination and fiber breakages which change the local stiffness of laminates. As these cracks propagate (in mode I and mode II), they interact with matrix-rich regions and the weave structure (see Fig. 13), resulting in substantial crack growth resistance and a better resistance to delamination, subsequent to the interlaminar fracture toughness, as it was highlighted in the literature $[11,29,32]$. The stress concentration at the crack tips leads to the creation of a plastic zone, whose expansion mainly depends on the matrix ductility, and is restricted by the bond-line thickness between adjacent layers (see Fig. 12). Thus, for a given impact force, the plasticization of the matrix starts earlier in $\mathrm{C} /$ PPS, and is more expanded than in C/PEEK and C/epoxy laminates in which plasticization is limited (see yield strengths in Table 1). As a result, the potential benefit of matrix-rich regions in wovenfabric laminates is the development of a significantly large plastic yield zone at the cracks tip as intralaminar and interlaminar cracks propagate [11]. It also means that the modes I and II interlaminar fractures toughness play important roles in determining the impact damage behavior of composites as previously reported [25]. In order to discuss the impact damage scenarios, it seems therefore relevant to recall the fracture toughness $G_{I c}$ of neat resins, and the interlaminar fracture toughness $G_{I C}$ and $G_{\text {IIC }}$ of woven-fabric laminates (see Table 3). As far the mode I interlaminar fracture is concerned, C/PEEK laminates are about twice tougher than C/PPS, and 6 times tougher than C/epoxy. From the $G_{\text {IIC }}$ standpoint, C/PEEK laminates are about 3 times tougher than C/PPS and C/epoxy. It means therefore that the intrinsic toughness of TP-based resins is not entirely beneficial to the reinforced polymer, and depends on how the matrix can modify the interlaminar fracture within the fiber network. As far the neat resin is concerned, the mode I interlaminar fracture is 8 times and 40 times higher in PEEK resin in comparison to PPS and epoxy resins respectively (see Table 3). Lastly, the low interlaminar toughness of epoxy-based laminates is consistent with the extensive delamination observed in these specimens (see Fig. 11). As a conclusion on the importance of interlaminar fracture toughness on the impact behavior, two distinct modes of failure were reported in the literature: a cleavage mode corresponding to fast crack propagation, in epoxy-based laminates whose mode I interlaminar fractures toughness is low (see Table 3 ), and a ductile mode corresponding to slow crack propagation, for TP-based laminates with a much higher $G_{I c}$ [47]. The mode II interlaminar fracture can be associated with a combination of stable crack growth preceding unstable crack growth, and matrix plasticization at the crack tips, depending on matrix ductility [48]. It could explain why the delaminated areas are larger in C/epoxy and C/ PEEK than in PPS-based laminates. Lastly, it was generally observed that matrix-rich areas and a strong interface bond promote unstable inter-laminar crack propagation (see Fig. 13a), whereas matrixpoor areas and a weak interface bond results in stable crack propagation through intralaminar cracks and possible debonding (see Fig. 13b). In addition to the toughness of the matrix, the crack growth may also be ascribed to the structure of the fiber network. The delamination crack at the woven-fabric laminate interface normally had multiple crack fronts, one for each warp yarn [11]. Once the crack propagation became rather unstable at a sudden load

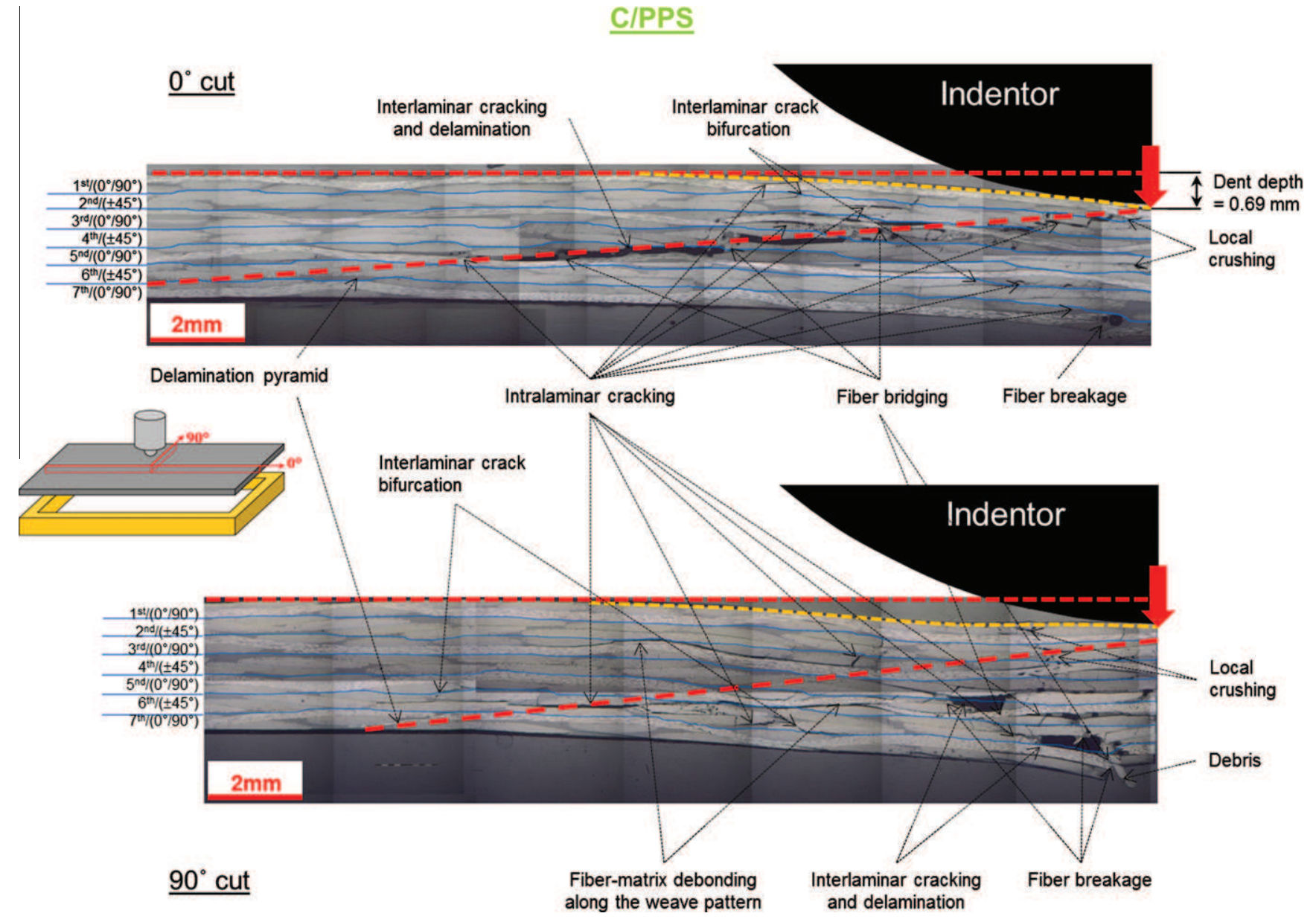

Fig. 10. Microscopic observations of C/PPS specimens impacted at $17 \mathrm{~J}$. 
drop on the force-displacement curve (see Fig. 3b), the whole crack front jumped forward which was then immediately arrested at the next undulation forming a continuous crack front (see Fig. 13a). The same mechanisms can generalize more or less as cracks propagate, until complete delamination of the laminate. In addition, the yarns transverse to the crack propagation direction also lead to interlaminar crack bifurcation and intralaminar cracking (see Figs. 9-11). These failure mechanisms are particularly instrumental in promoting fiber-bridging frequently taking place across the fracture surfaces. Indeed, when laminates are impacted to such a degree that matrix cracks just occur and begin to propagate, the cracks can propagate without breaking the fibers. Then, when the matrix cracks open, the intact fibers crossing the crack may close them, which are called fiber-bridging, on the crack surfaces and thus reduce the crack-opening-displacement and the stress intensity factors at the crack tips. Fiber-bridging mechanisms comprise debonding along the interfaces of matrix and bridging fibers, and frictional sliding along the debonded part of the interfaces. The bridging of macro-cracks by fibers only partially pulled out is an important source of toughness [49], and this mechanism is more likely to occur in tougher matrices, hence in TP-based laminates $[28,29]$.

\subsection{Impact damage scenarios}

The impacted specimens have been enrobed by an inclusion resin in order to prevent the relaxation of the damaged parts after cutting them. The microscopic observations of $0^{\circ}$ and $90^{\circ}$ cuts of impacted specimens have been carried out in order to explain the creation and propagation of the damage during these tests. Only the observations associated with a $17 \mathrm{~J}$ impact are presented in this section, because they are representative enough of all the types damages within the impacted laminates, and because the BVID is reached for the three materials at this energy level. In addition, the comparison between macroscopic observations and C-scan maps (see Fig. 7) gives qualitative and quantitative informa-

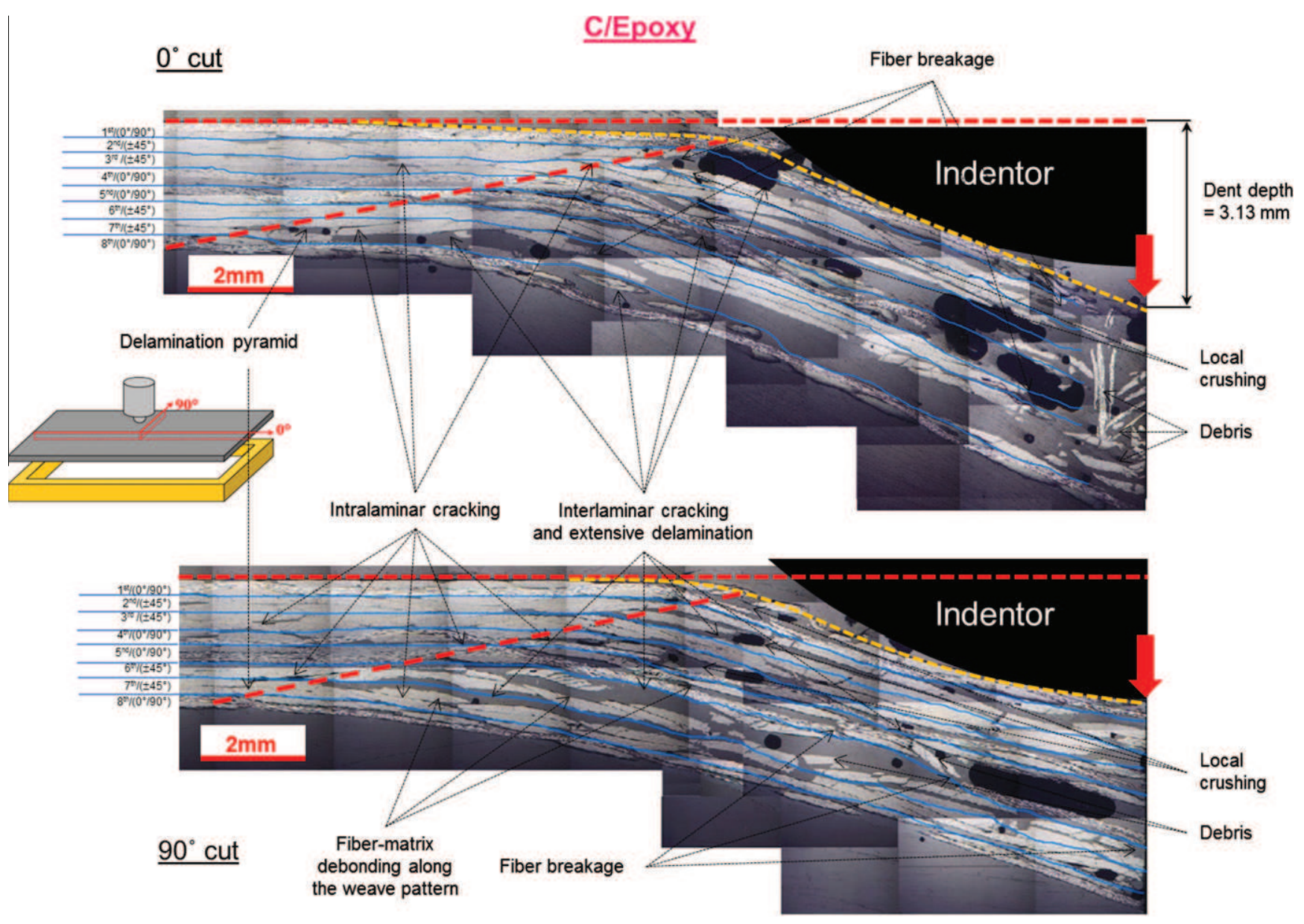

Fig. 11. Microscopic observations of C/epoxy specimens impacted at $17 \mathrm{~J}$.

Table 3

Interlaminar fracture toughness of tested materials - dent depth and delaminated surface for a $17 \mathrm{~J}$ impact energy.

\begin{tabular}{llll}
\hline & C/PEEK & C/PPS & C/epoxy (914) \\
\hline$G_{\text {IC }}\left(\mathrm{kJ} / \mathrm{m}^{2}\right)$ neat resin & $4[43]$ & $0.5-0.9[43]$ & $0.1[7]$ \\
$G_{I c \text {,initiation }}\left(\mathrm{kJ} / \mathrm{m}^{2}\right)$ carbon fiber woven-ply polymer & $1.1-2.1[29]$ & $0.85-1[25,28]$ & $0.35-0.5[32,34]$ \\
$G_{I I c}$,initiation $\left(\mathrm{kJ} / \mathrm{m}^{2}\right)$ carbon fiber woven-ply polymer & $2-4.9[30,44]$ & $1.8[28]$ & $1.5[11]$ \\
Dent depth at $17 \mathrm{~J}(\mathrm{~mm})$ impacted side & 0.69 & 1.13 & 3.13 \\
Delaminated surface at $17 \mathrm{~J}\left(\mathrm{~mm}^{2}\right)$ & 900 & 600 & 978 \\
\hline
\end{tabular}




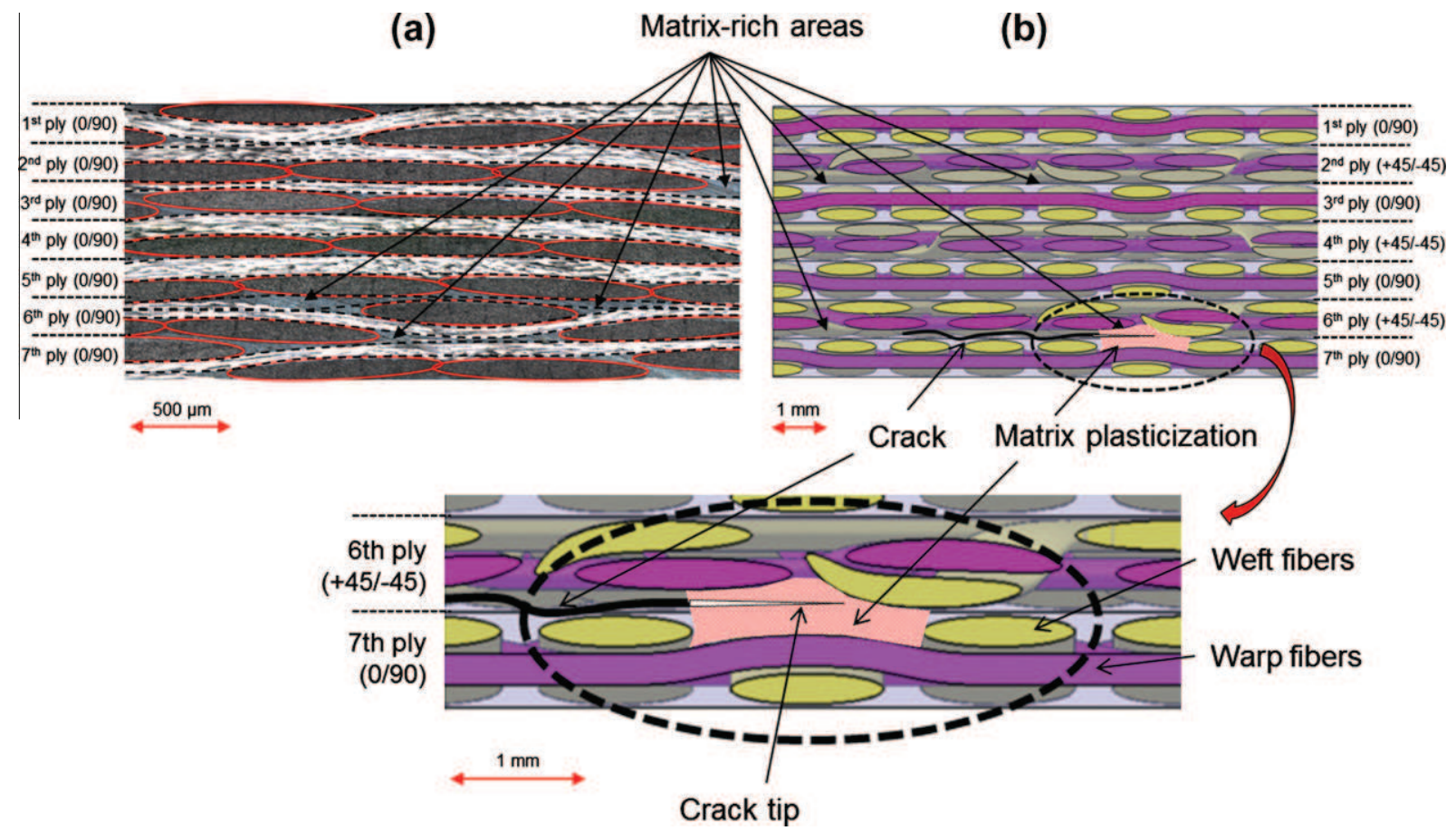

Fig. 12. (a) Edges microscopic observations of $[0]_{7}$ C/PPS laminates showing the specific intraply and interply structure of woven-ply laminates: matrix-rich areas and warp fiber bundles undulating over weft fiber bundles, and (b) matrix plasticization around the cracks tip in matrix-rich areas.

tion that can be correlated to the microscopic observations, and more particularly on the impact damage scenario. For each material, damage onset seems to be associated with two cracks (crack \#1 and crack \#2) along warp/weft directions for $6 \mathrm{~J}$ impact energy (see Fig. 5). As the impact force applied by the indentor increases, the specimen is subjected to bending. On the impacted side of

(a) Crack jumps and bifurcations: unstable crack growth

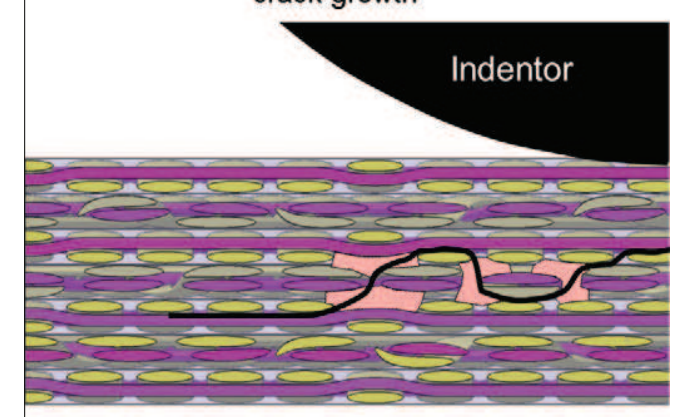

(b) Stable crack growth: very few interactions with matrix-rich areas

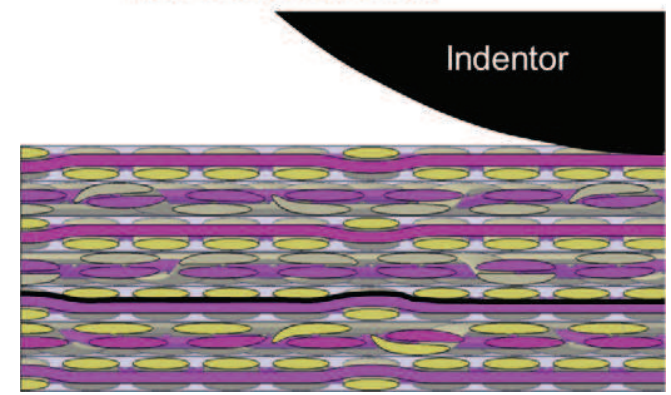

Fig. 13. Cracks growth: (a) stable intralaminar cracks, and (b) unstable interlaminar cracks characterized by jumps and bifurcations. specimens, the outer ply consisting of fibers in $0^{\circ}$ (warp) and $90^{\circ}$ (weft) directions is subjected to compressive loadings in both directions. The $0^{\circ}$ and $90^{\circ}$ cuts of specimens show that the first ply experiences local crushing (see Figs. 9-11). Such a crushing comes along with intralaminar and interlaminar cracks that are initiated from the circumference of the spherical indentor (see red dotted-circles on Fig. $5 \mathrm{c}$ and d). On the non-impacted side of specimens, the outer ply fibers are subjected to flexural loadings in both $0^{\circ}$ (warp) and $90^{\circ}$ (weft) directions. For an identical deflection, the curvature is more pronounced in warp fibers (see big side of the diamond-shape in Fig. 7). It justifies therefore higher stresses in warp fibers bundles because the stiffness is virtually the same in both warp and weft directions (see Table 1), and ultimately the warp fibers fail first. Such a breakage comes along with intralaminar and interlaminar cracks that are initiated from fibers breakage (crack \#1 - Figs. 5, and 9-11). The propagation of these cracks is brittle in epoxy-based specimens, and is more or less ductile in TP-based laminates depending on matrix ductility, and the distribution of matrix-rich areas. In addition, C/PPS proved to be prone to debonding at the fiber/matrix interface (see Fig. 10), as well as $\mathrm{C} /$ PEEK specimens to a lesser extent (see Fig. 9). When the $0^{\circ}$ fibers failed, the impact force is borne therefore by the $90^{\circ}$ fibers which also fail. Once again, fibers breakages come along with intralaminar and interlaminar cracks (crack \#2 - Figs. 5 and 9-11). In the studied materials, all the impact damage scenarios start from these initial damages, and importantly differ afterwards. In the $45^{\circ}$ oriented plies, the comparison of C-scan inspections and impact damage patterns on the back sides of specimens impacted at $17 \mathrm{~J}$ (Fig. 7) shows that the delaminated area has a diamond-shaped pattern. It suggests that delamination also takes place in the $[+45 /-45]$ plies as it is schematically represented in Fig. 14 . The $0^{\circ}$ and $90^{\circ}$ cuts (see Figs. 9-11) also show intralaminar cracks as well as the bifurcation of interlaminar cracks between [+45/-45] and $[0 / 90]$ plies at the crimps, where matrix may plasticize (see Fig. 13a). During impact, the contact area between the spherical indentor and specimens increases, and that is the reason why new $0^{\circ} / 90^{\circ}$ cracks appear on the non-impacted side of specimens. 
Thus, the mechanisms described above are going to generalize specifically in the laminates plies according to their orientation. Thus, intralaminar and interlaminar cracks are going to develop, propagate and coalesce in a pyramidal shape which will expand from the non-impacted side to the impacted side, as it can be observed in the $0^{\circ}$ and $90^{\circ}$ microscopic cuts of the tested materials (represented by an inclined red-dotted line in Figs. 9-11). This pyramidal damage is clearly observable in TP-based specimens, and more particularly in C/PEEK, but is less easy to define in epoxy-based laminates. On the non-impacted side of specimens, the diamondshaped damage results from the gradual breakage of fibers in warp and weft directions, and can be clearly observed at $25 \mathrm{~J}$ (see Fig. 5d). At increasing impact energy, the significant changes in the permanent indentation (see Fig. 2b) may be ascribed to the extension of this pyramidal damage along the $0^{\circ}$ and $90^{\circ}$ directions. Indeed, as the normal displacement increases during impact, the cracks localized along the pyramid axis open wider through the laminates' thickness, and grow in both warp and weft directions (by mode I and mode II failure) at increasing impact energy. Coming along with the pyramidal damage extension, delamination onset can be observed between the last two outer plies of the laminates. It develops therefore throughout the width of the specimens (in the $90^{\circ}$ direction - mode III shearing failure). Impact induced damages are schematically represented on Fig. 14. Based on the microscopic observations in the $0^{\circ}$ and $90^{\circ}$ directions, the damage mechanisms importantly differ from one material to another. In C/PEEK laminates, the initial damage consists in matrix cracking from which intralaminar and interlaminar cracks are initiated along the warp and weft directions. As the impact force increases, these cracks propagate. As the ultimate out-of-plane shear strength is significantly higher in C/PEEK specimens (see Table 1 ), there is relatively less shear matrix cracking in comparison to
C/PPS and C/epoxy laminates (see Fig. 14). As a consequence, fibers bear most of the impact force and eventually fail, hence justifying a cross-shape pattern on the non-impacted side. Contrary to C/PEEK laminates, the low ultimate out-of-plane shear strength of C/PPS laminates leads to matrix plasticization in matrix-rich areas and then shear matrix cracking, whereas it seems there is relatively less fibers failure in warp and weft directions. In 5-harness satin weave C/PPS laminates (the exact same material than the one investigated in this work), sudden jumps in the force-displacement curves and unstable crack propagation in mode I have been observed [28]. The mode II crack propagation also proved to be stable for reasons of matrix plasticization at the crack tips. Such an effect could also be associated with the weak adhesion at the fiber/matrix interface [42], resulting in an extensive debonding and fiber-bridging at the wake of cracks front (see Fig. 14). Finally, in C/epoxy laminates, there is relatively little damage on the upper ply (see Fig. 5), because an extensive delamination appears throughout the laminate's thickness at increasing impact energy. Thus, the outof-plane displacement associated with delamination is greater, and the impact force borne by C/epoxy specimens is lower than the one in TP-based laminates (see Fig. 3). Microscopic observations of $0^{\circ}$ and $90^{\circ}$ cuts revealed debonding of transversely oriented yarns at the crack plane, and crack branching around the debonded yarn. Debonding was found to occur periodically and was identified as a mechanism contributing to the fracture work. No indications of fiber-bridging were observed in the $5 \mathrm{H}$-satin weave carbon/epoxy composites (see Figs. 11 and 14).

\subsection{Permanent indentation}

From the damage mechanisms described above result a permanent indentation (see Fig. 2b). Another factor contributing to the
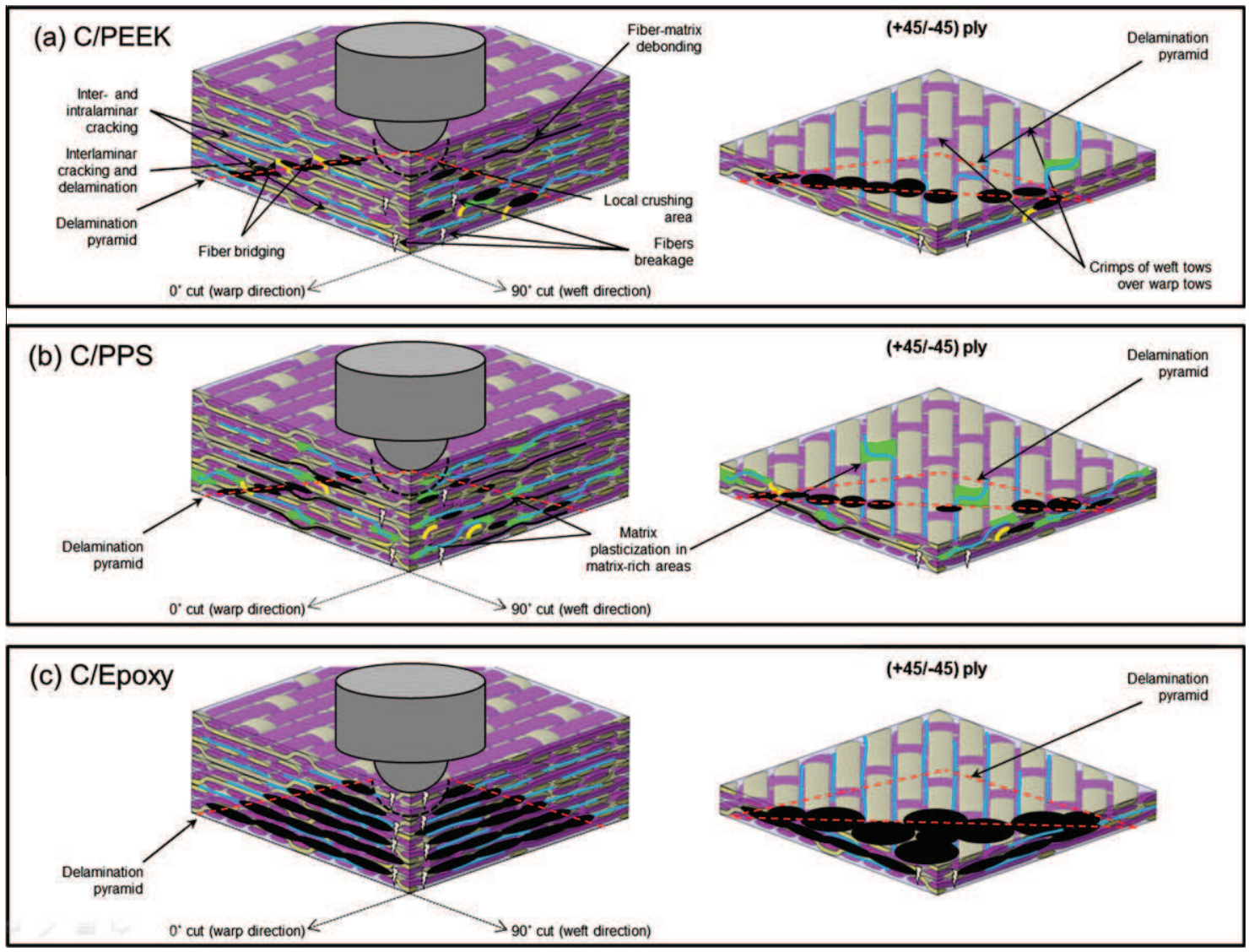

Fig. 14. Schematic representation of impact induced damages: (a) C/PEEK, (b) C/PPS, and (c) C/epoxy. 
increase of dent depth is the development of the diamond-shaped damage on the non-impacted side particularly in C/epoxy specimens and in C/PPS laminates to a lesser extent. Firstly, and particularly in the case of TP-based laminates, the matrix plasticization seems to play an important role in matrix-rich areas by locally leading to permanent deformations, hence contributing to the permanent indentation. Secondly, the permanent indentation seems to be reduced by the presence of fiber-bridging as it can be observed in TP-based laminates. Bridges prevent the plies from opening in mode I, and slow down the propagation of interlaminar and intralaminar cracks in modes II-III, ultimately reducing their extension and subsequent delamination for a given impact energy. Finally, while fibers gradually fail and cracks propagate in the $0^{\circ}$ and $90^{\circ}$ directions, the out-of-plane shearing of the layers localized under the damage pyramid lets the debris of broken fibers and matrix get in the fracture surface (see Figs. 9-11). These debris get stuck in these cracks and the adjacent layers, and create a sort of blocking system that prevents the broken parts of the specimen from getting back to zero level after the impact. The longer the cracks are, the more the debris can get in, creating a diamondshaped mark on the non-impacted side of the specimen, hence the permanent indentation. These mechanisms are instrumental in forming the BVID which is fundamental in damage tolerance [45].

\section{Conclusion}

From the present comparative study on the low velocity impact behavior of carbon woven-ply reinforced polymer composites, it results that C/epoxy laminates experience larger delamination than TP-based laminates. C/TP laminates are characterized by reduced damages (C/PPS laminates in particular), confirming that a tougher matrix can possibly be associated with better impact performances. In addition to the nature of the matrix, the reinforcement weave structure limits extensive growth of delamination, but fiber breakages are more common and appear at lower impact energies because of fiber crimps. The features and advantageous failure mechanisms are identified: inherent toughness of the fabric; the availability of matrix-rich regions at the fiber bundles crimp where plastic deformation can develop (in C/TP laminates); crack propagation along the undulating pattern of the yarns creating a large fracture surface area; and multiple crack delamination on the impacted side (particularly in epoxy-based laminates). In TP-based laminates, impact damage scenarios are similar at low impact energies. The delamination failure comes along with interlaminar and intralaminar cracks. They appear to be mode I failure mechanisms, defining a delamination pyramid under the impactor. As the impact energy increases, the cracks propagation seems to be driven by mode II and mode III shearing modes beyond this delamination pyramid. These failure mechanisms depend on many factors including the ultimate out-of-plane shear strength (higher in PEEK-based laminates) resulting in a more or less pronounced matrix plasticization at the crack tips. The interlaminar fracture toughness in modes I-II-III (reduced in epoxy-based laminates) is associated with possible fiber-bridging (not observed in C/epoxy). C/PEEK is therefore relatively less prone to shear matrix cracking, hence justifying a cross-shape pattern on the nonimpacted side when they fail. The poor fiber/matrix adhesion in C/PPS laminates results in an extensive debonding, and fiberbridging at the wake of cracks front. It could explain why the delaminated areas are larger in C/epoxy and C/PEEK than in PPS-based laminates. Lastly, the permanent indentation can be mainly ascribed to different mechanisms. On the one hand, the matrix plasticization seems to play an important role in matrix-rich areas by locally promoting permanent deformations in TP-based laminates.
On the other hand, fiber-bridging prevents the plies from opening in mode I, and slows down the propagation of interlaminar and intralaminar cracks in modes II-III. It reduces therefore their extension and subsequent delamination for a given impact energy. Finally, the debris of broken fibers and matrix get stuck in the cracks and the adjacent layers (particularly in C/epoxy laminates), and create a sort of blocking system that prevents the cracks and delamination from closing after impact.

\section{References}

[1] Hancox NL. An overview of the impact behavior of fibre-reinforced composites. In: Reid SR, Zhou G, editors. Impact behavior of fiber-reinforced composite materials and structures. CRC Press, Woodhead Pub. Ltd.; 2000.

[2] Cantwell WJ, Morton J. The impact resistance of composite materials-a review. Composites 1991;22(5):347-62.

[3] Jang BP, Kowbel W, Jang BZ. Impact behavior and impact-fatigue testing of polymer composites. Compos Sci Technol 1992;44(2):107-18.

[4] Abrate S. Impact on composites structures. Cambridge University Press; 1998

[5] Bibo GA, Leicy D, Hogg PJ, Kemp M. High-temperature damage tolerance of CRFP. Part 1: impact characteristics. Composites 1994;25(6):414-24.

[6] Bibo GA, Hogg PJ, Kemp M. High-temperature damage tolerance of CRFP: 2 Post-impact compression characteristics. Composites 1995;26(2):91-102.

[7] Jang BP, Huang CT, Hsieh CY, Kowbel W, Jang BZ. Repeated impact failure of continuous fiber reinforced thermoplastic and thermoset composites. J Compos Mater 1991;25(9):1171-203.

[8] Ishikawa T, Sugimoto S, Matsushima M, Hayashi Y. Some experimental findings in CAI tests of $\mathrm{CF} / \mathrm{PEEK}$ and conventional $\mathrm{CF} /$ epoxy flat plates. Compos Sci Technol 1995;55:349-63.

[9] Davies P, Riou L, Mazeas F, Warnier P. Thermoplastic composite cylinders for underwater applications. J Thermoplast Compos Mater 2005;18(5):417-43.

[10] Schrauwen B, Peijs T. Influence of matrix ductility and fibre architecture on the repeated impact response of glass-fibre-reinforced laminated composites. Appl Compos Mater 2002;9(6):331-52.

[11] Kim J-K, Sham M-L. Impact and delamination failure of woven-fabric composites. Compos Sci Technol 2000;60:745-61.

[12] Bibo GA, Hogg PJ. Review: the role of reinforcement architecture in impact damage mechanisms and post-impact compression behavior. J Mater Sci 1996;31:1115-37.

[13] Mili F, Necib B. Impact behavior of cross-ply laminated composite plates under low velocities. Compos Struct 2001;51(3):237-44.

[14] Aktaş M, Atas C, İçten BM, Karakuzu R. An experimental investigation of the impact response of composite laminates. Compos Struct 2009;87(4):307-13.

[15] Reis PNB, Ferreira JAM, Santos P, Richardson MOW, Santos JB. Impact response of Kevlar composites with filled epoxy matrix. Compos Struct 2012;94(12):3520-8.

[16] Morton J, Godwin EW. Impact response of tough carbon fibre composites. Compos Struct 1989;13(1):1-19.

[17] Prevorsek DC, Chin HB, Bhatnagar A. Damage tolerance. Design for structural integrity and penetration. Compos Struct 1993;23(2):137-48.

[18] Bartus SD, Vaidya UK. Performance of long fiber reinforced thermoplastics subjected to transverse intermediate velocity blunt object impact. Compos Struct 2005;67(3):263-77.

[19] Reyes G, Sharma U. Modeling and damage repair of woven thermoplastic composites subjected to low velocity impact. Compos Struct 2010;92(2):523-31.

[20] Ghasemi Nejhad MN, Parvizi-Majidi A. Impact behaviour and damage tolerance of woven carbon fibre-reinforced TP composites. Composites 1990;21(2):155-68.

[21] Wang H, Vu-Khanh T. Damage extension in carbon fiber/PEEK cross ply laminates under low velocity impact. J Compos Mater 1994;28(8):684-707.

[22] Gao S-L, Kim J-K. Cooling rate influence in carbon fibre/PEEK composites. Part III: impact damage performance. Composites A 2001;32(6):775-85.

[23] Aymerich F, Priolo P, Vacca D. Static loading and low-velocity impact characterization of graphite/PEEK laminates. In: Proceedings of the international conference on advanced mater, Hurghada, Egypt; 1998.

[24] Vedula M, Koczak MJ. Impact resistance of cross-plied polyphenylene sulfide composites. J Thermoplast Compos Mater 1989;2(3):154-63.

[25] Spamer GT, Brink NO. Investigation of the CAI properties of C/PPS and C/APC-2 TP materials. In: Proceedings of the 33rd international SAMPE symposium: materials-pathway to the, future; 1988.

[26] Ma C-CM, Lee C-L, Chang M-J, Tai N-H. Effect of physical aging on the toughness of CFR PEEK and PPS composites. Polym Compos 1992;13(6):441-7.

[27] Davies GAO. Design methodology to improve damage tolerance in composites. In: Brite Euram 3159-89 contract report, second ed., Dept. of Aeronautics, Imperial College, London; 1993.

[28] De Baere I, Jacques S, Van Paepegem W, Degrieck J. Study of the mode I and mode II interlaminar behavior of a carbon fabric reinforced TP. Polym Test 2012;31(2):322-32.

[29] Davies P, Benzeggagh ML, De Charentenay FX. The delamination behavior of carbon fiber reinforced PPS. In: 32nd International SAMPE, symposium; 1987. p. 134-46. 
[30] Lachaud F, Lorrain B, Michel L, Barriol R. Experimental and numerical study of delamination caused by local buckling of TP and TS composites. Compos Sci Technol 1997;58:727-33.

[31] O'Brien K. Composite interlaminar shear fracture toughness giic: shear measurement or sheer myth? Tech Memorandum, NASA; 1997.

[32] Alif N, Carlsson LA, Boogh L. The effect of weave pattern and crack propagation direction on mode I delamination resistance of woven carbon composites. Composites B 1998;29:603-11.

[33] Kim J-K, Leung LM, Lee SWR, Hirai Y. Impact performance of a woven fabric CFRP laminate. Polym Compos 1996:4:549-61.

[34] Funk JG, Deaton JW. The interlaminar fracture toughness of woven graphite/ epoxy composites. NASA tech paper 2950; 1989

[35] Siow YP, Shim VPW. An experimental study of low velocity impact damage in woven fiber composites. J Compos Mater 1998;32(12):1178-202.

[36] Jegley DC. Compression behavior of graphite-thermoplastic and graphiteepoxy panels with circular holes or impact damage. NASA tech paper, 3071; 1991.

[37] Baker DJ. Mechanical property characterization and impact resistance of selected graphite/PEEK composite materials. NASA tech Memorandum 102769, AVSCOM tech, report 90-B-012; 1991.

[38] Atas C, Sayman O. An overall view on impact response of woven fabric composite plates. Compos Struct 2008;82(3):336-45.

[39] Karaoğlan L, Noor AK, Kim YH. Frictional contact/impact response of textile composite structures. Compos Struct 1997;37(2):269-80.
[40] Chaudhuri J, Ghoe GH, Vinson JR. Impact characterization of graphite fiber reinforced thermoplastic laminates. J Reinf Plastics Comp 1993;12(6):67-685.

[41] Aucher J, Vieille B, Taleb L. Influence de la température sur le comportement mécanique de stratifiés tissés thermoplastique ou thermodurcissable. Rev Comp Mater Av 2011;21(3):317-43.

[42] Vieille B, Aucher J, Taleb L. Woven ply thermoplastic laminates under severe conditions: notched laminates and bolted joints. Composites B 2011;42(3):341-9.

[43] Tropis A, Thomas M, Bounie JL, Lafon P. Certification of the composite outer wing of the ATR72. J Aero Eng 1994;209:327-39.

[44] Akkerman R, Warnet LL, Van de Ven EC. Impact damage in woven fabric reinforced composites. In: Proceedings of the 10th international conference on textile comp TEXCOMP'10, Lille, France; October 2010.

[45] Abdallah EA, Bouvet C, Rivallant S, Broll B, Barrau J-J. Experimental analysis of damage creation and permanent indentation on highly oriented plates. Compos Sci Technol 2009;69:1238-45.

[46] Berglund LA. Thermoplastic resins. In: Peters ST, editor. Handbook of composites. London: Chapman \& Hall; 1998.

[47] Moore DR, Seferis JC. Toughness characterization of carbon fiber PEEK laminates. Pure Appl Chem 1991;63(11):1609-25.

[48] Carlsson LA, Gillespie JW, Trethewey BR. Mode II interlaminar fracture of graphite/epoxy and graphite/PEEK. J Reinf Plastics Comp 1986;5(3):170-87.

[49] Kardomateas GA, Carlson RL. A micromechanical model for the fiber bridging of macro-cracks in composite plates. J Appl Mech 1996;63:225-33. 